\title{
Contenidos biográficos de valor formativo para la educación del siglo XXI. Memorias escritas por mujeres de tiempos en que han sido olvidadas
}

Biographical Contents of Formative Value for the $21^{\text {st }}$ Century Education. Memories Written by Women of Times When they Have Been Forgotten

\section{Paquita Sanvicén Torné}

\section{Resumen}

Este artículo muestra el interés de incorporar los egodocumentos de mujeres, textos narrativos en primera persona, como tipología de fuentes formativas mas allá de los grados y asignaturas de historia, especialmente en los de contenido sociológico. Los datos que se presentan se centran en la recuperación y visibilización de las acciones de las mujeres que vivieron durante la Guerra Civil en las comarcas de Lleida. La metodología se basa en el análisis cualitativo sistemático de las únicas 6 memorias escritas por ellas sobre sus trayectorias vitales en ese periodo. El análisis de los espacios de socialización, los roles y vidas cotidianas que ellas recuerdan y escriben aportan muestras que poco tienen que ver con la imagen pasiva con que se las ha etiquetado socialmente. Entre los ámbitos de competencias complejas que los universitarios deben desarrollar, se encuentran el pensamiento crítico, la capacidad de comprender a los demás, la empatía y la inteligencia interpersonal. Reconocer los elementos que construyen la desigualdad de género para tratarla y evitarla esta en la base de esas competencias. Las relaciones de género son también el resultado de acciones, transformaciones, rupturas y continuidades acaecidas en los procesos sociales en momentos presentes y pretéritos. Los primeros no pueden explicarse ni entenderse sin los segundos. Aunque los datos que se presentan se centran en ese período histórico concreto, las reflexiones y el modelo de trabajo pueden extrapolarse a otros momentos y situaciones tanto históricas como actuales, por ello se presenta una propuesta didáctica para tratarlas en las aulas.

\section{Palabras clave}

Biograficidad, egodocumentos, biografía formativa, sociología de la educación, poder, educación, género.

\section{Abstract}

This article shows the interest of incorporating the egodocuments of women, narrative texts in the first person, as a typology of formative sources beyond the degrees and subjects of history, especially those with sociological content. The data presented focuses on the recovery and visibility of the actions of women who lived during the Civil War in the regions of Lleida. The methodology is based on the systematic qualitative analysis of the only 6 memories written by them about their life trajectories in that period. The analysis of the spaces of socialization, the roles and daily lives that they remember and write contribute samples that have little to do with the passive image with which they have been socially labeled. Among the areas of complex competencies that university students must develop, are critical thinking, the ability to understand others, empathy and interpersonal intelligence. Recognize the elements that build gender inequality to address it and avoid it is at the base of those skills. Gender relations are also the result of actions, transformations, ruptures and continuities that occur in social processes in present and past moments. The former can not be explained or understood without the latter. Although the data presented focuses on that specific historical period, the reflections and the work model can be extrapolated to other moments and situations both historical and current, therefore a didactic proposal is presented to treat them in the classrooms.

\section{Keywords}

Biograficidad, egodocumentos, formative biography, sociology of education, power, education, gender. 
«De entrada me repito, antes y ahora, que las historias de mujer,no deben tener demasiado interés para

la posteridad». Dolors Sistac (2012: 8)

\section{Introducción}

Este artículo tiene como objetivo mostrar el interés de incorporar la lectura, análisis y reflexión de egodocumentos ${ }^{2}$ escritos por mujeres en los programas formativos de los estudiantes universitarios actuales, mas allá de los grados y asignaturas de historia, especialmente en los de contenido sociológico. Los datos y las reflexiones que aporta forman parte de un proyecto de largo recorrido iniciado durante el curso 2014-2015 a partir de la constatación de los vacíos de información y reflexión existentes en los estudiantes universitarios sobre el papel y las aportaciones que han hecho las mujeres en el proceso de construcción de la sociedad en que viven ${ }^{3}$. Aunque los datos que se presentan se centran en el período específico de la Guerra Civil, creemos que las reflexiones y el modelo de trabajo es útil para entender otros momentos y situaciones históricas y actuales.

El interés científico, formativo y educativo de las biografías narradas en primera persona no es nuevo. Tampoco lo es su teorización des del campo de la sociología de la educación. Aunque introducida recientemente en las universidades españolas (Hernandez, 2007; Hernández \&Villar, 2015), aparece ya en los años noventa de la mano de Peter Alheit. Nosotros hemos llegado hacia su estudio dando un rodeo a través de la sociología de la memoria iniciada en la primera mitad del xx por Halbwachs (2004). Biografías, narrativas de vida, o memorias son básicas en la construcción de los sujetos. Sin ellas probablemente desconoceríamos aun más los hechos del pasado social, político, bélico y económico del siglo xx. Con toda seguridad desconoceríamos más aun las aportaciones de las mujeres que lo vivieron, trabajaron y lucharon des de los diferentes ámbitos de la cotidianidad. Las biografías son «el complemento de la historia oficial que omite 'lo particular'», en palabras de Jané (Jané, Miralles, Fernández, 2013: 12). Hacemos énfasis en las escritas ya que tienen útiles elementos singulares. Para el enfoque que perseguimos, la falta de un investigador que dirige el recuerdo tiene una ventaja: la libertad de quien narra. Lo que se escribe es lo que el protagonista quiere escribir, lo que oculta es lo que quiere ocultar. Lo visible y lo oculto es elegido por quien firma en primera persona. Se narra libremente, de nominaliza y se oculta libremente, siendo reflejo del entorno y pensamiento social desde el que se sitúa.

Sociología e historia son campos afines e indisolubles. Todos los actos cotidianos del presente son a su vez históricos. En la sociedad actual cambiante y acelerada prolifera la publicación de biografías de los llamados protagonistas de la «historia reciente». Antes y ahora, hay una pregunta latente... ¿Dónde están las mujeres? Es un hecho que antes y ahora son ellos los que escriben mayoritariamente. Las razones hablan del interés socialmente atribuido a sus biografías por su representatividad social, política y económica. Como afirma Bettina Dausien el «lugar social género está no solo determinado horizontalmente sino que

2 Aunque en el articulo los textos que se analizan son memorias personales escritas y publicadas por mujeres, la mirada del proyecto en general se amplía a relatos escritos en primera persona sean publicados o manuscritos. Ante la diversidad conceptual existente para designar esas fuentes, utilizamos el concepto genérico e inclusivo egodocumentos en el sentido que le otorgó Jacques Presser «autobiografías, diarios, memorias, cartas personales y textos en que el autor escribe acerca de si mismo, de sus asuntos y sentimientos». (Dekker, 2002: 13).

3 VII Jornadas Mujeres e igualdad de trato en el mundo rural (15-18 octubre 2014) organizadas conjuntamente por el Centro Dolors Piera de Igualdad de Oportunidades y promoción de las mujeres de la Universidad de Lleida; el Grupo de Estudios sobre Sociedad, Salud, Educación y Cultura del Departamento de Geografía y Sociología de la Universidad de Lleida y el Ayuntamiento de Alcoletge que tiene la titularidad del Centro de Interpretación del Patrimonio de la Guerra Civil «Ermengol Piró». Las jornadas se dedicaron al tema «Los campos de batalla de las mujeres durante la Guerra Civil en el territorio de Lleida. Recuerdo, olvido y transferencia). 
tiene un efecto acumulativo en la perspectiva vertical» (originalmente en Dausien, 1996: 579-587 citada en Hernandez, 2007:73-85).

Le Goff afirmaba que el pasado no es historia sino su objeto, a la vez que las biografías que tampoco lo son sino que actúan como uno de los objetos para la recuperación del pasado y, con el la historia. (Le Goff, 1991).

«Solo los individuos, las personas recuerdan», afirma Halbwachs. Ante los datos, los hechos históricos, la realidad de lo que pasó en realidad es el hecho, lo que es cierto; la memoria es realidad construida y depende del entorno social. El lenguaje usado pertenece a una representación social de un tiempo y un lugar. (Halbwachs, 2004: 7). Igualmente hay un significado cultural tradicional adscrito al concepto vida cotidiana. Un espacio identificado como doméstico, particular, privado por tanto sin protagonismo. Sin embargo, a poco que lo observemos, comprobamos que todos nos desarrollamos en marcos de vida cotidiana, con sus rutinas, sus espacios de soledad e interrelaciones. Cada una de las esferas profesionales, sociales, lúdicas forman parte de la cotidianidad de individuos y grupos y cada parte está conectada con las demás en una influencia mutua. El sesgo incide en el hecho que el pasado de las mujeres esté infraestudiado porque a su vez las mujeres se han biografiado poco o nada, en determinados contextos y periodos temporales. Por ello, la construcción cultural secular, escrita por quienes tienen el poder y lo biografían repetidamente, identifica mujer-espacio privado-tareas subalternas. Aunque el análisis concienzudo de las biografías demuestra su invalidez, ese sesgo planea y configura los espacios sociales significativos. Es justamente por ello que el cambio de mentalidad real hacia la equidad e igualdad de género (mas allá de los discursos y manifestaciones bienintencionadas) aun en el 2018 no se haya normalizado completamente.

\section{Objetivos}

El objetivo general de la investigación en curso está trazado des del interés sociológico por un lado y formativo didáctico por otro. En el primero, busca analizar la construcción de la imagen proyectada socialmente de las mujeres que vivieron en nuestros pueblos y ciudades, a partir de cómo son olvidadas, recordadas y narradas en la memorialística local. En el segundo -empezando por la visibilización de un momento histórico aun vivo en nuestros pueblos y ciudades- busca aportar datos, evidencias y reflexión sobre las diferentes «trincheras» de las vidas cotidianas de las mujeres. El objetivo final es que los estudiantes universitarios puedan completar y (re)construir los conocimientos y la imagen que tienen sobre ellas.

Interesa ver los espacios que la memoria escrita les ha reservado, - y les ha negado- para configurar para la posteridad sus realidades como sujetos. Empezando a indagar en una primera fase en los egodocumentos de la Guerra Civil se prevee ir avanzando, posteriormente, por periodos históricos sucesivos hasta la actualidad (dictadura, transición...).

\section{Objetivos específicos}

a) Localizar e inventariar diarios, autobiografías, memorias, dietarios escritos por protagonistas que relatan sus vivencias durante el periodo bélico en el territorio de Lleida y comarcas

b) Identificar los egodocumentos de autoría femenina, contextualizarlos, y analizar el contenido para analizar y tipificar sus características particulares como habitantes de territorios determinados; los espacios de socialización y formación que recuerdan y recrean como sujeto y mujer, sus trayectorias vitales, sus profesiones, su vida cotidiana, etc. 
c) Analizar el contenido de todos los egodocumentos publicados tanto de autoría femenina como masculina, para identificar e interpretar a fondo como -que similitudes y que diferencias- es incorporada y tratada la presencia femenina en los relatos escritos por los unos y por las otras.

c.1. Identificar y analizar las diferencias existentes entre el contenido de los relatos de autores y autoras, en términos de lenguaje utilizado, descripciones, valoraciones, espacios, roles, tipos y actividades de las mujeres que aparecen en ellos.

d) Identificar que legado, que construcción de sus trayectorias vitales y qué papel e imaginario social se ha trasladado a las generaciones jóvenes.

El contenido de este artículo pone en relación datos iniciales de la primera fase del desarrollo de los tres objetivos.

\section{Metodología}

El enfoque metodológico es cualitativo, aunque se incorpora una mirada estadística básica a efectos de inventario de fuentes. Para desarrollar en primer objetivo específico se está llevando a cabo des de noviembre de 2014 un proceso de localización sistemático de egodocumentos ${ }^{4}$ y posterior catalogación en una base de datos propia ${ }^{5}$. Se ha empezado por un proceso de identificación de categorías descriptivas simple para avanzar posteriormente al análisis de las estructuras narrativas o estructuras de acontecimientos desde la perspectiva del análisis de redes. (Verd, 2006).

Se han identificado 74 títulos y 4 manuscritos inéditos publicados desde 1941. De los 78, solo 6 están escritos por mujeres. La Tabla 1 recoge los datos básicos de esas 6 autoras y del texto de referencia.

Tabla I. Memorias de autoría femenina centradas en las comarcas de Lleida

\begin{tabular}{|c|c|c|c|c|c|}
\hline AUTORA & $\begin{array}{c}\text { LUGAR } \\
\text { NACIMIENTO }\end{array}$ & $\begin{array}{c}\text { AÑO } \\
\text { NACIMIENTO }\end{array}$ & TÍTULO & $\begin{array}{c}\text { AÑO } \\
\text { PUBLICACIÓN }\end{array}$ & EDITORIAL \\
\hline Isabel Piulats & Bellvís (comarca Pla d’Urgell) & 1910 & $\begin{array}{l}\text { Memorias de Doña Isabel Piulats Reñé viuda de la Guerra Civil Española } \\
\text { de } 1936 \text { a } 1939 \text {. Escritas por ella misma. }\end{array}$ & 19796 & Autoedición (Bell-Hoch) \\
\hline Mercè Briansó & Albagès (comarca Garrigues) & 1913 & D'un temps, d'un poble & 1984 & Virgili \&Pagès, S.A. (Lleida) \\
\hline Mercè Briansó & Albagès (comarca: Garrigues) & 1913 & Una àvia sentimental. (Recull de vivencies, exemples i opinions) ${ }^{7}$ & 1987 & Virgili \&Pagès, S.A. (Lleida) \\
\hline Lola Farrera & Bellvís (comarca Pla d’Urgell) & 1919 & Posta de sol. Algunes pàgines de la meva història. ${ }^{8}$ & 1998 & Pagès editors (Lleida) \\
\hline Carme Garrofé & Térmens (comarca Noguera) & 1931 & $\begin{array}{l}\text { Protestants sota el franquisme. Repressió religiosa contra la comunitat de } \\
\text { Térmens (1939-1960) }\end{array}$ & 2010 & Pagès editors (Lleida) \\
\hline Dolors Sistac & Lleida (comarca Segrià) & 1922 & Temps de llucar. Segona memoria I. ${ }^{10}$ & 2012 & Pagès editors (Lleida) \\
\hline
\end{tabular}

\footnotetext{
4 Por razones de criterios que aparecen explicados en el proyecto las fuentes inventariadas se refieren exclusivamente a las de autoría en primera persona que vivieron los hechos directamente. Quedan fuera del proyecto las aportaciones literarias o biográficas hechas por escritores o biógrafos en tercera persona.

5 Las categorías identificadas son: autor, sexo, edad, año publicación, edición/manuscrito, territorio de donde se narran los hechos, período narrado, hechos narrados, número de personajes, número de personajes hombres, numero de personajes mujeres, frecuencia de aparición de unos y otros, relación entre ellos, estructuras narrativas.

6 Aunque el DL de la edición es de 1979 y de una imprenta de Bellpuig, la portada del relato lleva la anotación precisa «Bell.lloch, julio de 1978», suponemos por tanto que lo escribió un año antes de su publicación

7 Traducción del título al castellano: «Una abuela sentimental. (Recopilación de vivencias, ejemplos y opiniones)».

8 Traducción del título al castellano: «Puesta de sol. Algunas páginas de mi vida».

9 Traducción del título al castellano: «Protestantes bajo el franquismo. Represión religiosa».

10 Traducción del título al castellano: «Tiempo de brotar. Segunda memoria I».
} 
Para el segundo objetivo se está siguiendo un método de identificación de ítems y posterior vaciado y ordenación del contenido ${ }^{11}$.

Para el tercer objetivo se han seguido durante 3 de las tareas universitarias de los estudiantes de primer curso con los que tratamos. Se ha pretendido identificar cuando y como incorporan las aportaciones de las mujeres que vivieron ese período en sus tareas académicas de desarrollo libre. Se muestran algunas evidencias básicas en el apartado siguiente.

\section{Vacios de información que muestran las tareas académicas sobre las trayectorias vitales de las mujeres durante la guerra civil}

Nuestra experiencia en la asignatura de Sociología con estudiantes universitarios de primero nos permite comprobar que existe un relevante vacío de conocimientos que afecta la interpretación de la historia pasada y la interpretación del presente. Ello a pesar que ese periodo de la historia es tratado y estudiado en la formación obligatoria preuniversitaria. Fundamentamos esta afirmación en el análisis de los resultados de una de las tareas académicas obligatorias que realizan. La tarea trata sobre identificar un cambio social relevante de las últimas décadas. ${ }^{12}$ Los datos cuantitativos de las tareas que han elegido temas relacionados con ámbitos relacionados con el género se presentan en la Tabla $2 .{ }^{13}$

Tabla 2. Relación entre el conjunto de tareas presentadas y el número (en absolutos y porcentual) de las que tratan sobre el tema mujer/mujeres

\begin{tabular}{cccc}
\hline CURSO & $\begin{array}{c}\text { TAREAS } \\
\text { PRESENTADAS }\end{array}$ & $\begin{array}{c}\text { TEMÁTICA } \\
\text { SOBRE MUJERES-GÉNERO }\end{array}$ & \% SOBRE EL TOTAL \\
\hline $2014-2015$ & 50 & 15 & $30 \%$ \\
\hline $2015-2016$ & 68 & 17 & $25 \%$ \\
\hline $2016-1017$ & 97 & 17 & $17,5 \%$ \\
\hline
\end{tabular}

\section{Tabla 3. Relación entre la cantidad de tareas presentadas y la relación de temáticas que presentan}

\begin{tabular}{ccl}
\hline CURSO & \multicolumn{1}{c}{ TAREAS } & TEMÁTICAS ESPECÍFICAS \\
\hline $2014-2015$ & 15 & - El rol de la mujer en la familia (3) \\
& & - La mujer en el ámbito laboral (7) \\
& - La mujer hoy (2) \\
& - La situación de la mujer en la sociedad (3) \\
& - Mujer y entorno/mundo laboral (7) \\
& - Mujer en la familia (3) \\
& - Evolución del papel de la mujer (3) \\
& - Mujer en la sociedad (2) \\
& - Mujer y política (2) \\
&
\end{tabular}

11 Se trabaja con la totalidad de los textos indistintamente ya que uno de los objetivos es comparativo. Se identifica y analiza la representatividad que tienen las mujeres que aparecen en el conjunto del relato, se tipifica la categoría mujer bajo todas sus dimensiones, se codifica n las relaciones de poder entre las personas que aparecen en los relatos y se tipifica el lenguaje utilizado para narrarla y describirla. Aunque es un proceso complejo por la cantidad de textos y la exhaustividad de la información que se pretende analizar, se pretende presentar una publicación específica a finales de año para utilizarla como material didáctico en el ámbito de sociología de género para los próximos cursos.

12 Concretamente, lo que se les pide es elegir un ámbito/tema; describir la situación inicial; identificar que ha cambiado; porque; que elementos han contribuido al cambio; alcance social de la nueva situación; problemáticas no resueltas de la situación precedente; nuevas problemáticas generadas.

13 Las diferencias de cantidad de tareas presentadas por curso están relacionadas no solo con el numero de matriculados sino con los acuerdos para hacer las tareas (en grupo de 2, de 3 o individual) que son variables por años. 


\begin{tabular}{lll}
\hline 2016-2017 & -Mujeres y ocupación (1) \\
& - Cambios en el ámbito domestico y laboral (2) \\
& - Evolución mujer en la sociedad (5) \\
& - Cambios en el mundo laboral y social (9) \\
\hline
\end{tabular}

Tal como se observa en los datos de las tablas anteriores (2-3), profundizar y saber mas sobre los cambios sociales que han afectado a las mujeres hasta la actualidad tiene un índice de interés discreto. Mas interesante es ver la preferencia de temas de los estudiantes que si han hecho esa elección y como construyen y justifican el proceso que explican. El tema mayoritario que tratan (tabla 3) son los cambios en el mundo laboral y social. La lectura atenta de las tareas permite observar que el $98 \%$ presentan el olvido sistemático del 36 al 39 como si fuera un espacio temporal vacío donde no hubieran existido las mujeres. En el apartado «Situación anterior»o «Historia» que, en general, tienen todas las tareas de acuerdo con la estructura formal obligada, un $70 \%$ de estudiantes se remontan a períodos anteriores al xx y todos sin excepción se centran en la Segunda República y como si de un contínuum se tratara enlazan directamente con la dictadura franquista. Es significativo porque la elección del tema es libre y libremente hay elegido el ámbito laboral, político, etc. Significativo también que no hay ninguna búsqueda de datos sobre las profesiones ejercidas por mujeres durante el periodo bélico (maestras, enfermeras, oficinistas, modistas...), ni sobre las responsabilidades políticas que muchas de ellas ejercieron tanto en el frente como fuera de él, ni sobre las feministas que también actuaron en ella. Tampoco se hace evidente la consciencia sobre que las hubo o las podía haber. Mucho mas significativo, y preocupante, es que el ámbito del alcance del proceso de cambio que se debía relatar era España o Catalunya.

Creemos que no les podemos achacar la responsabilidad del tipo de formación recibida. Lo que no se explica, no existe y las mujeres tradicionalmente no se han explicado o se han explicado muy poco. A la vista de ejemplos como estos que podemos observar en el día a día universitario, cabe plantearse seriamente la responsabilidad docente. Des de la historia pero también des de la sociología de la educación, es urgente incidir en la formación de las generaciones actuales deshaciendo tópicos y llenando de contenido la invisibilidad estructural en que quedan las mujeres.

\section{La necesidad de recuperar i valorizar las memorias de mujeres como objeto forma- tivo, aun en la sociedad digital}

La defensa de la recuperación y el uso formativo de las biografías se inscribe en el panorama actual de reflexión sobre cómo construir la ciudadanía intelectual y responsable en la era informacional. Hay interesantes aportaciones sobre la adaptación de la enseñanza de las ciencias sociales a los nuevos estilos de aprendizaje que tienen en su base la preocupación por la construcción de la persona y las personas del siglo xxi, la enseñanza de los valores, el respeto, la diversidad (Prats, Santacana, 2015). Así mismo, la Carta del Consejo de Europa sobre la educación para la ciudadanía democrática y la educación de los derechos humanos promulga como contenidos básicos «el diálogo intercultural, la conciencia del valor de la diversidad y la igualdad en todos sus niveles, incluida la igualdad entre hombres y mujeres, el respeto mutuo, la dignidad humana, el diálogo, los valores compartidos y la no violencia en la resolución de problemas y conflictos» (Consejo de Europa, 2010:10). En momentos como los actuales, en los que aspectos como la desigualdad, la violencia de género, la discriminación por estereotipos culturales que afectan mas a mujeres que a hombres, la pregunta que a menudo nos hacemos es: ¿podemos de verdad plantear respuestas si no hemos resuelto satisfactoriamente la construcción cultural adscrita de manera desigual al género? ¿si aun continúan en la estructura profunda de la sociedad normas culturales que marcan lo masculino de lo femenino? 
La observación sobre la educación, y sobre nuestra historia inmediata pone de manifiesto con claridad que continua siendo evidente la desigualdad existente en la visibilización de las estrategias y vivencias de las mujeres como sujeto social activo en la evolución social. Carrasco y su equipo, analizando como enseñar la diversidad de la construcción del género en la sociedad actual, afirman:

«Se impone la necesidad de seguir investigando para ampliar la perspectiva de los estudios de las mujeres como categoría de análisis de los procesos educativos y organizativos para reinterpretar la construcción social, las relaciones, el liderazgo, la comunicación, el poder y las relaciones humanas». (Carrasco, Moreno, Coronel, 2009: 161).

Ángeles Calero, desde la investigación universitaria apela al

«conocimiento de la historia (que) debe hacernos personas conocedoras de cómo puede transcurrir nuestro futuro como sociedad a partir de la manera que hacemos el camino: abrir a las mujeres el universo reservado a los hombres, poner en duda el imaginario social estereotipado, motivar la excelencia individual (...) nos permitirá disfrutar de lo mejor de cada miembro de la comunidady, (...) beneficiarnos de todo lo maravilloso que puede hacer la mitad de la población que ha sido silenciaday desaprovechada». (DDAA, 2010:11).

Desde la vertiente didáctica, los profesores Edda Sant y Joan Pagés demuestran que las mujeres son, aun en pleno siglo xxi, invisibles en la enseñanza de la Historia. Citando a Fernández (2001: 85) concluyen que

«si la historia de las mujeres replantea la historia, su enseñanza, su visibilidad debe (...) romper el modelo de análisis que identificaba el sujeto masculino como sujeto universal (...) y convertir en objeto de estudio temáticas ligadas a problemas y situaciones tradicionalmente consideradas como propias de mujeres». (Sant \& Pagés, 2011:144).

Los autores afirman que solo así se conseguirá una enseñanza de la historia que fomente la ciudadanía democrática entre los y las jóvenes y desarrolle su consciencia histórica a la vez que construye un tiempo en igualdad de condiciones. El enfoque tradicional de la investigación ha primado la recuperación de las mujeres políticas, activistas, militantes, feministas, represaliadas... y ha relegado al olvido la acción del resto de las mujeres que quedaba fuera de estos ámbitos. Desde el punto de vista territorial se han buscado mayoritariamente los espacios de mayor complejidad: grandes ciudades dejando espacios locales yermos de información. Lo que no explica, no existe, y las mujeres tradicionalmente ni se han explicado ni han sido explicadas. A la vista de ejemplos como estos y otros que podemos observar en el día a día académico, cabe plantearse seriamente la responsabilidad docente. Desde la historia pero especialmente desde la sociología de la educación es urgente dotar a los universitarios de parámetros que les ayuden a interpretar los hechos sociales deshaciendo tópicos y llenando de contenido la invisibilidad estructural existente.

Aun siendo solo cinco, los escritos analizados reflejan territorios, generaciones, clases sociales, entornos familiares, educativos, creencias religiosas y trayectorias distintas. Este hecho afianza un aspecto destacado para la construcción social de las realidades que plantean: su heterogeneidad. Contrariamente al imaginario social que homogeneiza y simplifica, hubo tantas maneras de vivir (en) ese periodo como mujeres, territorios, contextos, situaciones económicas y profesionales, etc. El imaginario colectivo construido ha tendido a invisibilizar la complejidad y minimizarla. Aun siendo solo 5 no retratan un tipo de 
mujer sino cinco de muy distintos en, y desde, realidades, roles y vivencias dispares. Esa evidencia rompe de entrada los estereotipos homogeneizadores que recorren el género y muestra que el constructo la mujer es irreal, no existe; lo que existe son las mujeres. En el apartado siguiente (5.1) se presentan algunos de los aspectos analizados siguiendo los objetivos de investigación. En primer lugar, se muestran las motivaciones de las autoras que les llevan a escribir con perspectivas distintas desde sus presentes. A su vez, se hace énfasis en la construcción lingüística y conceptual de las autoras a partir del discurso de los prologuistas, cuando los hay, y la propia autoconstrucción de ellas mismas. En segundo lugar, se presentan datos del análisis de los espacios de sociabilidad que conforman las mujeres como individuo y sujeto antes, durante e inmediatamente después de la guerra civil. En ese sentido se destaca el relato que hacen de su relación con los progenitores. En tercer lugar, se aproxima a algunas de las relaciones significativas de poder y género que se dirimen en estos espacios entre los distintos autores que los integran.

\subsection{La complejidad de las vidas cotidianas descritas por ellas mismas, mas allá de estereotipos y simplificaciones}

\subsubsection{Autoconstrucción y construcción del sujeto}

Todas ellas escriben y publican pasados los 65 años $^{14}$, cuando los hechos de la Guerra Civil tenían entre 5 y 26 años $^{15}$. La distancia entre el tiempo de los hechos vividos y el de los hechos narrados influye sin duda en el contenido y el enfoque del relato. De todos el que contiene más fuerza dramática es el de Piulats. En apenas treinta páginas autoeditadas se evidencia fortaleza y vindicación impregnada de un sentido reproche hacia la colectividad. Sin nadie que le prologue, termina con un epílogo donde muestra la intención que persigue con su publicación:

«iDe esas mujeres heroicas, si se pueden así llamar, como yo lo hago, se llenarían los pedestales. Pero el mundo los guarda para sus ídolos, para los que hacen ruido, exhibiéndose y gritando. Mientras que las anteriores, lo sufren todo calladamente, sin que nadie se dé cuenta. Para mí, son las mujeres más valientes y dignas de llegar a los pedestales». (Piulats 1978: 3).

Ciertamente, representa el testimonio vivo de una de las tipologías de mujer producto de la Guerra aun pendiente de estudio: las jóvenes viudas.
«Ha habido y hay gente que merecerian ser destacados y pasan como desapercibidos, mejor dicho, bumillados y esto, no debería ser. Me refiero a esas pobres viudas de guerra que con su estoica y callada soledad, han sabido sobrevivir y llevar adelante con mil apuros y estrecheces a sus hijos, buérfanos de padre. Para mi éstas han sido más heroicas y merecedoras de toda ayuda material que muchos que les llaman "famosos" sea por lo que sea». (Piulats 1978: 3).

Piulats pertenece a la categoría de mujeres que narran desde la perspectiva de sus vivencias traumáticas (Arfuc, 2013: 73). Sin duda, su relato tiene el interés añadido de parecer escrito con un enfoque de reivindicación colectiva, en representación de las viudas de la Guerra.

Aunque con un estilo de redacción más contenido y elaborado, el caso de Briansó es parecido. El texto visibiliza y reivindica el conocimiento de las vicisitudes pasadas por la comunidad evan-

\footnotetext{
14 Piulats debía tener 67 años cuando escribió sus memorias, y 68 cuando fueron publicadas. Briansó 71 cuando publicó la primera versión y 74 cuando salió a la luz el texto que analizamos. Farrera tenía 79 cuando publicó el conjunto de sus relatos y mas de 75 cuando los fue publicando en la revista local. Una nota a pié de página en las memorias de Sistac sabemos que el 1968 publicó una primera parte aun inédita, tenía 46 años. En el momento de terminar de escribir la segunda parte tenía 78 años, se publicó un año después. Garrofé escribe y publica a los 79 años.

15 Piulats tenía 26; Briansó 23; Farrera 17; Sistac 14 i Garrofé 5.
} 
gélica en un pueblo de la comarca de la Noguera (Térmens), perseguida también por el ejército nacional y, después, por el franquismo.

Para Sistac, la única escritora profesional del conjunto, deja entrever una cierta añoranza afectiva hacia el pasado vivido por la cual desea recuperarlo antes de morir (Sistac 2012: 9). Briansó por su parte reconoce que narra sus vivencias para legar su modelo de conducta a las madres modernas y a los nietos (Briansó 1987: 59). Farrera se apoya en Fernando Pessoa para justificar el compromiso de escribir. «...narrar significa hacer la historia de la vida y hacer la historia de la vida significa comprenderla. Creo que es muy importante narrar y también lo es escuchar». (Farrera 1998: 15). Con todo, coincide con Briansó en el hecho que los destinatarios de la narración son sus hijos y nietos para que descubran su infancia y facetas de su vida que cree que desconocen.

\subsubsection{Quien prologa también construye}

De los cinco textos, solo tres están prologados. Por hombres en todos los casos. El de las memorias de Farrera lo escribe su hijo, intelectual de reconocido prestigio nacional. La descripción que hace de la obra materna está llena de tópicos:

«... este es un texto marcadamente femenino, tanto por su temática como por el lenguaje usado para desarrollarla. Las personas que han estudiado la literatura femenina -básicamente mujereshan insistido en un punto característico: el tono claramente autobiográfico de la obra literaria de las mujeres (...) El lenguaje femenino no hace más que reflejar una realidad, la de las habilidades sensitivas y comunicativas de las mujeres (...) La gama de colores de la ternura es casi infinita en el espacio sensitivo de una mujer y el espectro de los dolores un verdadero rosario (...). (Serrano, 1998: 8-9).

Serrano explicará que su madre pasa de puntillas por los hechos sin querer dañar a nadie. Esa característica, junto al silencio, aparece, relatadas por ellas mismas, en Piulats y Brianso, calificado como lo natural por ser mujer. Por serlo, ni para ellos ni para ellas -excepto para Sistac que empezó a hacerlo pronto- escribir no debía formar parte de sus tareas, ni de hecho de las reconocidas como de actividad femenina. Escribir no deja de ser un acto de buscar una notoriedad más allá del ámbito estrictamente familiar donde los que han escrito su historia las ha anclado. Con todo, parece que ni para ellas mismas lo que hacían era algo transcendente. Briansó en el epílogo escribe

«más de uno de los que puedan leer estos escritos se preguntaran: ¿Cómo es que nunca habiamos sabido nada de las particularidades de la Mercè Briansó y Seró, después de tantos años de conocerla? Yo les respondería: que hubiera ganado yo dando explicaciones? Lo que cuentan son los hechos». (Briansó, 1987: 89).

Briansó misma explica que antes de escribir lo consultó con su marido... «para saber si le sabría mal o no» (Briansó, 1987: 89). No hubiera escrito si su opinión hubiera sido contraria a ello. Una acción claramente diferencial por razón de género sin duda. Muestra la decisión de escribir mediatizada en primera instancia por el hecho de ser mujer y dependiente de la gestión relacional de la dominación de género. Cabe destacar ese hecho ya que de las más de setenta memorias escritas por hombres que hemos estudiado, ninguna recoge una demanda de permiso a su mujer. 
Sistac describe su carácter ya en la primera página a partir del hecho que su padre quería un niño, efecto que guía sus elecciones posteriores como mujer «enseguida me obstinaría a elegir caminos por donde solo transitaban hombres. Un padre frustrado era la mejor cosa que me podía pasar». (Sistac, 2012: 7).

Farrera justifica la sencillez y brevedad de los capítulos diciendo «Mi cultura es flojita» (Farrera, 1998: 15). Briansó empieza su relato con un atributo específico: «Lo que me gustaba mucho era leer. Mi cuñado Rosendo se hacía llevar el periódico. No recuerdo cual, pero no podré olvidar nunca que llevaba un suplemento femenino». (Briansó, 1987: 5).

Con atributos de feminismo y cultura aparece definida en el prologo de su editor. Este escribe sobre Briansó: «en su narración detectareis el alma de una mujer catalana de nuestras tierras que se anticipa a una reivindicación social y feminista. (...) un Feminismo en el cual se armoniza el ideal que Platón albiraba y que el Cristianismo penetró maravillosamente». (Briansó, 1987: 4). No deja de ser relevante está suma del pensamiento del filósofo con la tradición religiosa, toda vez que afianza doblemente la imagen femenina ligada a tareas del ámbito privado y madres y esposas modelo.

En sentido contrario, es también paradigmático el enfoque del prologuista de Carme Garrofé, Vicenç Villatoro un prestigioso escritor de ámbito nacional. Lo es por ser el único que no utiliza artificios emotivos ni tópicos de género. En cuatro páginas solo una vez prescinde utiliza el substantivo «niña de postguerra». En el resto utiliza dos maneras de nominar la autora: su nombre y apellido y el genérico «persona». «El libro que tenemos en las manos son las memorias de una persona nacida en un pueblecito de Catalunya antes de la guerra que explica su infancia». (Garrofé, 2010: 9).

\subsection{Espacios formativos, de sociabilidad y relaciones de género}

Hemos identificado los espacios sociales en los que las autoras describen sus recuerdos y se recuerdan a ellas mismas. De manera esquemática se han recogido los más relevantes en la Tabla 4, procurando una ordenación conforme aparece en los textos. Por la desigualdad de los relatos, en los que los recuerdos se evocan libremente, es complejo situar el momento escrito en un tiempo concreto. Al no mantener siempre una estructura cronológica, los marcos espaciales se agrupan en los tres periodos que, aun con intensidad desigual, aparecen en todas los textos: antes, durante y inmediatamente después de la Guerra.

El material acumulado a partir del análisis de las personas y actitudes que aparecen en los relatos es muy extenso. A causa de las limitaciones de extensión de este artículo esbozamos solo algunos de ellos como ejemplo.

\section{Tabla 4. Síntesis de los espacios del recuerdo de las acciones antes, durante y inmediatamente después de la G.C.}

\begin{tabular}{|c|c|c|c|c|c|}
\hline & ISABEL PIULATS & MERCÈ BRIANSÓ & LOLA FARRERA & CARME GARROFÉ & DOLORS SISTAC \\
\hline Antes de G.C. & $\begin{array}{l}\text { - casa/pueblo familiar } \\
\text { - escuela } \\
\text { - calle(juegos) } \\
\text { - casas de servir } \\
\text { - casa casada }\end{array}$ & $\begin{array}{l}\text { - corres pondencia } \\
\text { - barbería } \\
\text { - casa hermana } \\
\text { - Barcelona } \\
\text { - academia costura }\end{array}$ & $\begin{array}{l}\text { - casa/pueblo familiar } \\
\text { - escuela } \\
\text { - juegos/fiesta mayor } \\
\text { - Barcelona: dependienta/criada }\end{array}$ & - casa/pueblo familiar & $\begin{array}{l}\text { - ciudad familiar } \\
\text { - mercado } \\
\text { - instituto } \\
\text { - fiesta mayor }\end{array}$ \\
\hline
\end{tabular}


Contenidos biográficos de valor formativo para la educación del siglo xxl. Memorias escritas por mujeres de tiempos en que han sido olvidadas.

\begin{tabular}{|c|c|c|c|c|c|}
\hline Durante G.C. & $\begin{array}{l}\text { - casa casada } \\
\text { - calle } \\
\text { - pueblos/casas de refugio } \\
\text { - casa casada } \\
\text { - cartas } \\
\text { - calles } \\
\text { - hospital } \\
\text { - casas de refugio }\end{array}$ & $\begin{array}{l}\text { - cola del racionamiento } \\
\text { - casa de refugio }\end{array}$ & $\begin{array}{l}\text { - casa refugio/pueblo familiar } \\
\text { - ocio }\end{array}$ & $\begin{array}{l}\text { - Barcelona } \\
\text { - calle } \\
\text { - Francia } \\
\text { - Orfanato de Montalbà } \\
\text { - Centre de Seta } \\
\text { - aula } \\
\text { - teatro }\end{array}$ & $\begin{array}{l}\text { - instituto } \\
\text { - casa } \\
\text { - casas de refugio } \\
\text { - hospital } \\
\text { - lejanía } \\
\text { - cine } \\
\text { - calle }\end{array}$ \\
\hline $\begin{array}{l}\text { Inmediatamente } \\
\text { después de G.C }\end{array}$ & $\begin{array}{l}\text { - casa casada } \\
\text { - casa familiar } \\
\text { - casas de servir }\end{array}$ & $\begin{array}{l}\text { - casa casada } \\
\text { - academia }\end{array}$ & $\begin{array}{l}\text { - pueblo familiar/casas } \\
\text { familiares } \\
\text { - teatro }\end{array}$ & - casa/pueblo familiar & $\begin{array}{l}\text { - casa } \\
\text { - instituto }\end{array}$ \\
\hline
\end{tabular}

Como se observa en la tabla 4, a pesar de las diferencias existentes entre las autoras ya expuestas anteriormente, en todos los casos aparecen espacios comunes: la casa familiar, la escuela, los espacios de ocio. Otros son compartidos por algunas, como los espacios de trabajo sin remuneración: casas de servir, establecimientos... Este enfoque de estudio, basado en identificar sus espacios de sociabilidad nos parece altamente didáctico e interesante al poder detectar y ubicar en contexto las estructuras relacionales que se establecen en ellos y analizarlas.

\subsubsection{El padre/marido siempre presente, la madre no tanto}

Destacamos el hecho de que los primeros personajes que acaparan los recuerdos más profundos y detallados sean masculinos y no femeninos ya que es una constante significativa. Igual que lo es que el padre sea caracterizado en todas ellas con descripciones más amplias y con calificativos de valoración superior que las madres y que ellos protagonicen los recuerdos más relevantes ${ }^{16}$.

Piulats en los primeros párrafos de su relato explica

«Jo tenía una gran pasión por mi padre, pues siendo niña me daba cuenta de sus cualidades extraordinarias. (...) Aprendió a leer cuando ya era padre de todos sus hijos. Puso en ello una voluntad tan grande que llegó a ser representante de la Azucarera (...) cargo de cierta importancia». (Piulats, 1978: 5).

Su madre en cambio es calificada con una sola frase: «Mi madre (no hay que decirlo) fue ejemplo de todo» (Piulats, 1978: 5). Poco más sabemos de ella, aunque más adelante explica que «se lo vendía (los animales de la granja) para comprar ropa de vestir a sus hijos». (Piulats, 1978: 5-7)

En Farrera el personaje activo y de toma de decisiones está representado por su padre. A su madre le dedica un corto capítulo de la cual destaca

«Era una mujer sencilla, poco habladora, de buena presencia y bonita. (...) Siempre la recuerdo con un pequeño en el regazo, dándole el pecho». (Farrera, 1998: 27).

También las primeras palabras de Sistac son para su padre. La madre aparecerá páginas después. Curiosamente en ningún momento explicita que es su madre, se deduce por los apellidos: «La María Sanvicen Clavé (1896-1983) había ido a costura». Las pocas referencias a ella van ligadas siempre a la imagen de mujer dedicada a las labores del hogar.

Garrofé sigue el mismo patrón. La primera voz que aparece en la primera página es la paterna

16 El enfoque del artículo no permite profundizar sobre ese interesante tema sobre el cual se está trabajando en el análisis de contenido contrastándolo con las memorias de autoría masculina en las cuales aparecen también padres, madres, novias y esposas, con descripciones, valoraciones y un protagonismo en el conjunto del relato significativamente diferente. 
«Recuerdo la voz. de mi padre diciéndome que iría a vivir a Francia con mi madre y mis primos».

(Garrofé, 2010:15).

Significativamente, en un relato diacrónico de la evolución de la comunidad religiosa, les dedica dos capítulos específicos: La historia de mi padre y El reencuentro con mi padre. (Garrofé, 2010: 37-52; 97-108). No hay ningún capítulo dedicado a la madre, aunque el retrato con que la describe sea hecho en términos combativos. Al pié del tren que debía llevarlos a Francia, sus nombres no aparecen en la lista de embarque.

«Tal como era de esperar, conociéndola, mi madre no aceptó de ninguna manera una negativa». (...) (Garrofé, 2010: 22).

En una situación de mal uso de comida que ella descubrió:

\section{"Carmen, la luchadora (...) estaba decidida a dirigirse directamente al comité para ponerles al} corriente». (Garrofé, 2010: 25).

\subsubsection{Las casas, en plural}

El calificado como casa es el primer espacio presente en los recuerdos. Utilizamos significativamente el plural, casas, para poner en valor como objeto de estudio un espacio etiquetado tradicionalmente como banal, identificado con la domesticidad y las tareas del hogar y la familia vistas como coactivas para las mujeres. Una mirada amplia permite observar la complejidad de los diferentes espacios casa-de diferentes estructuras, territorios, situaciones, y ejerciendo en ellas diversas responsabilidades-.

El conjunto de los espacios tipificados en los que se construyen las interrelaciones narradas son físicos, tangibles. En Briansó no aparece la descripción de la casa tradicional. Ella otorga un protagonismo específico a un espacio diferente que solo encontramos en sus memorias, como si un antecedente fuera del actual espacio virtual: el de la correspondencia. Enamorarse de un desconocido a través del correo electrónico ha sido en esta d un filón temático la filmografía de comedia rosa. El relato de Briansó, que remite al lector a algún momento sin precisar de los años treinta del siglo pasado, serviría como guión, aunque el canal no sea el correo electrónico sino el postal. Aunque nada explica del núcleo familiar ni de la educación paterna, ni de la suya, la protagonista se retrata con una autonomía en la toma de decisiones frente a sus padres y familia que, situando los hechos en la moral de la época, en este caso de la inmediata preguerra, parece excepcional:

"(en un fascículo de un diario) habia un anuncio: Doy clases de catalán a quién pueda interesarle. Preferible a jóvenes (...) Firmaba A.T.LL. (...) Inmediatamente bice la solicitud para ser una de sus alumnas. (...) iqué divertido era recibir una carta semanal! (...) Mis padres decían "te distraerás del trabajo de la academia de costura" Y yo les respondia: No sufráis, que esto me divierte y me instruye». (Briansó, 1987: 5)

\subsubsection{Casas de refugiados}

El progresivo avance del conflicto bélico provoca a su vez el desplazamiento de la población de retaguardia hacia pueblos y zonas que ofrecían más seguridad. Todas las autoras relatan, con mayor o menor detalle, el recuerdo del viaje y las vivencias de refugiadas. 
Hombres, mujeres, jóvenes, adultos, niños, ancianos, conocidos y desconocidos, que deben reorganizar las estructuras de relación, de distribución del espacio y las responsabilidades que conlleva la supervivencia. Los lugares que las autoras nombran sirven poco más que para identificar en el mapa la ruta seguida. En los relatos se diferencia entre los refugios, espacios puntuales donde guarecerse bajo las bombas y las casas de familiares y conocidos de otros pueblos donde se refugiaban de manera más o menos permanente. Los relatos de las narradoras nos ofrecen pocos detalles sobre cómo se organizaban esos espacios compuestos sobre todo por mujeres, abuelos y niños. Ése es un ámbito desconocido. En algunos de los pocos detalles que incorporan aparecen siempre la actividad resolutiva de las mujeres y, en este caso, el papel secundario de los hombres de la familia. Sirvan como ejemplos de otros tantos, fragmentos del relato de Sistac y Piulats:

"La abuela Bepeta (...) empezaría a hacer negocios con los mandos" para proveerlos de alimentos frescos que ellos no tenían». (Sistac 2012, 100).

"Yo dormía en una cama grande con la Milagros de Balaguer y el niño. Pasamos los tres una mala noche. Me acuerdo que ella me dijo: "Ya puedes llorar que este niño se te muere"(...) Tenian por costumbre venir mis padres de Bellvís (...) y al ver al niño tan malo me dijo mi madre: "No te apures! Yo iré a buscarla. (a la suegra que sabia de enfermedades). $Y$ se fue andando sola, hasta Bell Iloch, llegando tan pronto como pudieron"》. (Piulats, 1978: 16).

\subsubsection{Casas y tiendas para servir}

En Piulats las casas de servir son presentes des del principio del relato hasta prácticamente el final. La primera mención va ligada a sus 11 años y al recuerdo de su primer viaje a Barcelona de criada. Lo que explica, aunque fruto de la necesidad, aparece como un intercambio mercantil entre mujeres, una de ellas su madre.

"A medida que mis hermanas y yo ibamos creciendo, mi madre nos sacaba de la escuela para ponernos de niñeras. (...) Dinero no cobrábamos. Solamente la comida. Con todo, eso era un alivio para mi madre". (Piluats 1998: 10) "entonces se me llevó una señora bija de Bellvís (la cual no quiero nombrar) (...) vino a casa en busca de una niñera, siendo yo en aquel momento, la unica libre. De momento protesté (...) pero me lo pintaron tan bien que cedí. (...) ¡Como no lloré Diós Mio! (...) ique poca atención tuvieron conmigo siendo tan niña!” (...) Transcurridos unos meses nos marchamos a Bellvís. Yo me arrojé a los brazos de mi madre, llorando amargamente diciéndole que no quería regresar a Barcelona porque me trataban muy mal"》. (Piulats 1998: 11).

Aun así, será mandada por su madre otra vez a Barcelona y continuará de criada en diferentes casas hasta los 22 años edad que se casa. De todo ese largo período en hogares ajenos la autora nada relata. (Piulats 1998: 10-12)

\subsubsection{Escuela/Instituto}

Los contenidos y experiencias educativas producidos en espacios no formales - para utilitzar una terminología actual- tienen un amplio protagonismo en su construcción como persona y como mujer. El protagonismo de la escuela y el instituto es escaso. Briansó nada relata. Por edad, Garrofé iniciará la escuela en el exilio francés. El resto lo harán en sus pueblos y ciudades natales. 
Piulats y Farrera la abandonaron pronto. (Piulats, 1978:9). Farrera recuerda que dejó la escuela a los 10 años al nacer su hermano para cuidarlo. Aunque «suerte tuve que me gustaba mucho leer, como todos los hermanos y ello me instruyó un poco y me ayudó mucho». Sus lecturas eran lecturas de Folch y Torres y novela rosa que intercambiaban con las amigas de su misma edad. Una vez más, la figura paterna será crucial:

«... nuestro padre no quería que las leyéramos. Decía que nos llenaban la cabeza de pájaros. Estaba contento cuando veía que leiamos Julio Verne. (...) Tenía muchos volúmenes de este escritor y muy bien encuadernados». (Farrera, 1998: 49).

De la madre no hay ningún dato en ese sentido. Sistac es quien más tiempo pudo dedicar a formarse. La decisión de estudiar fue de su padre. Su madre opinaba que debía aprender a coser. A diferencia de las demás, el ambiente estudiantil la marcó:
«el curso del instituto 37-38 se trasladó a otro edificio (...) Sabiamos (en casa por una emisora clandestina) que el frente de Aragón se acercaba peligrosamente. Unas cuantas compañeras de curso, posiblemente las más avanzadas, organizaban en el aula una especie de mitines familiares (...) deduzco que aquellos quinto y sexto de bachiller alojaron un ramillete de futuras mujeres sen- sibilizadas con vista al futuro, Europa y el mundo. Con el triunfo de los nacionales todo quedaría roto». (Sistac, 2012: 96).

\subsubsection{Espacios de ocio: Ambiente de guerra: cine, teatro, calle}

Solo Isabel Piulats y Lola Farrera rememoran espacios de juego antes de la guerra, aunque de maneras muy diferentes. Piulats, con la vivencia de la pobreza, recuerda la escasez de juguetes, la mirada, narices y mocos pegados al escaparate de la tienda de juguetes inalcanzables, y como ella y los demás críos los construían con lo cual eran felices. Su relato incorpora estrategias de colaboración con las iguales y a su vez diferencias por razón de género que suenan aún actuales, más allá de los materiales y la tipología del juego.

"“... con otras niñas como yo hacia muñecas de trapo viejo, con serrín y paja, con ojitos, nariz. y boquita, que eran una maravilla. Asi mismo caritas con alambre y colchón y finalmente unas balancitas con cajas de betún, para vender carne, que eran trocitos de coly alguna verdura más." (...) "Los niños también se hacian sus propios juguetes, como pelotas hechas con bilo de algodón y trapos. (...) Además el buli y las bitllas"». (Piulats,1979: 9).

Farrera, desde una posición social y económica acomodada, vincula la felicidad al juego y la amistad vinculado a les Firetes, espacios de tiovivos que caracterizan las fiestas mayores de antes y de ahora, al recuerdo de una amiga íntima y el padre de ésta.

«(...) Éramos como hermanas (...) en la Fiesta Mayor siempre nos llevaba a las ferias y no ayudaba a subir a los caballitos y a las barquitas». (Farrera, 1998: 7).

La Fiesta Mayor continúa al recordar Farrera sus 11 años, preadolescente, su última fiesta mayor con la amiga ya «hablando de chicos» y «empezando a sacar la cabeza por el entoldado del baile». Reaparece en este caso el rol de la figura paterna con un nuevo calificativo: seguridad.

"Al atardecer su padre y el mío nos venían a buscar y nosotras, con nuestras tiernas manos bien cogidas a las fuertes manazas de los padres nos sentiamos seguras y protegidas». (Farrera, 1998: 34). 
El cine es, aún en periodo de Guerra solo para las que viven en la capital Lleida, un espacio de educación informal:

«en Lleida, las sesiones de cine continuaron (...) el grupito que compartiamos curso tendríamos ocasión de asistir a dos películas memorables (...) La tolerancia, para el tiempo de la guerra civil y en una pequeña ciudad como la nuestra era casi absoluta. La temible censura (...) vendría después. Para chicas de quinto o sexto de bacbillerato, ávidas de saber y de conocer tantas cosas que nos habian estado vedadas, espectáculos como estos nos permitian ver más allá de nuestras ventanas habituales». (Sistac 2012: 95).

\subsubsection{Espacios de trabajo}

Farrera emprendió un viaje desde su pueblo a la capital por trabajo. A diferencia de otras, no la empujó la necesidad sino la aventura:

«el año 36, justo al cumplir los 16 años pedí a mi padre que me dejara ir a trabajar a Barcelona». (Farrera, 1998: 43).

Explica las condiciones paternas para el viaje: dependienta si, criada no. El viaje a la capital acompañada por un primo queda ilustrado con la imagen de las colas de chicas ante una posibilidad de trabajo:

«cuando llegábamos donde pedían una chica para hacer de dependienta encontrábamos una cola de 25 o 30 chicas». (...). (Farrera, 1998: 45).

Aunque nunca trabajó de criada, Sistac, ya refugiada, ejerció de enfermera obligada.

«Tenía quince años y tenía estudios. (...) Me tocaría servir en el Hospital de la Sangre como registradora de los heridos que iban Ilegando.(...) Metida a la fuerza en aquella aventura, conocí médicos y mediquitos, enfermeras improvisadas que lucian uniforme como si se tratara de un film de guerra».(Sistac, 2012: 106).

\subsubsection{Relaciones de poder y violencia}

Es significativo analizar los espacios de conflicto y violencia latente que van apareciendo junto las referencias a la lucha, muertes, detenciones, persecuciones entre las distintas familias y bandos ideológicos. A su vez, ellas recuerdan los otros espacios y actores de la violencia. De su relato se desprende la existencia de relaciones violentas que no siempre están vinculadas con el dominio del hombre sobre la mujer y no siempre pasan durante la Guerra Civil. Destacan las que resultan de tratos de desigualdad de clase, de estatus y de poder entre mujeres.

Piulats relata situaciones de acoso obligada a trabajar como criada sin quererlo. Farrera, que explica también su experiencia como criada y dependienta relata haber vivido una proposición de trabajo deshonesta si quería mantener el trabajo:

"“... con un bablar meloso me dijo que ganando lo mismo podía quedarme como camarera en su casa. Hasta me echó flores, me decía que tenía un tipo muy bonito y que sería una camarerita muy guapa. No lo acepté". (...) "Tenía unos morros salidos, siempre iba llena de joyas y llevaba unos escotes exagerados y su piso parecía una casa de citas"》. (Farrera, 1998:44-45). 
Farrera misma explica la vuelta a su pueblo natal, después de proclamada la Guerra y las preguntas del comité republicano al cual se dirigieron para tener el salvoconducto correspondiente para viajar:

«Dijimos que habiamos dejado a los amos y que íbamos a casa de nuestros padres. Nos trataron muy bien, éramos trabajadoras y nos trataron como compañeras. Nos preguntaron: ¿Vuestros antiguos amos se han portado siempre bien con las dos? ¿Alguien de la casa ha intentado alguna vez. abusar de dos jovencitas como vosotras?». (Farrera, 1998: 48).

En Sistac aparece el acoso sexual intentado por militares del bando franquista. Los padres evitaron que se consumara. Dada a la literatura ya desde pequeña, el suceso no suponía una situación de peligro sino de emoción:

"Uno de los acompañantes más asiduos del capitán era un teniente elegante (...) Para una adolescente ávida de sensaciones nuevas, el ambiente debia ser propició al encantamiento y dejarse llevar. (...) Una mañana solicitó permiso para llevarme con su caballo a coger fruta. (...) La madre me cogió del brazo como si fuera a perderme». (Sistac, 2012: 103-104).

Briansó narra una proposición parecida, esta vez de un oficial médico, al cual delató las caricias en el pelo y el regalo de un peine.

«yo creo que las mujeres somos más perspicaces y madre le dijo a padre "No la dejes sola. No te vayas hasta que ellos (el médico franquista y un ayudante) no se hayan ido"». (Briansó, 1998: 25).

Nos parece ciertamente relevante que -excepto en el relato de Garrofé por ser una niña de seis años-aparezcan este tipo de vivencias rescatadas desde sus miradas. Aunque no es el objeto de este artículo, ni el espacio permite profundizar en el análisis comparado, apuntamos solo que sus testimonios contrastan la visión de circunstancias parecidas explicadas en algunas de las memorias masculinas. Sirva un ejemplo de ellas. Jesús Arnal recuerda que:

"La mujer no tenia valory así se convertía en un instrumento de placer (...). En general la moralidad entre las mijeres jóvenes estab completamente relajada, excepto en algunos casos muy loables. Eso era la consecuencia natural de las circunstancias por las cuales se atravesaba. Por un lado el poco valor de la vida. Se decía "vivamos que mañana podemos morir. Por otro la gran miseria y la necesidad de desplazarse y muchas veces claudicarpara obtener alimentos"》. (Arnal, 1997: 177).

\section{Una propuesta reflexiva para la formación de los estudiantes universitarios}

Los flujos incesantes de intercomunicación característicos de la sociedad digital construyen y reelaboran permanentemente la realidad y su percepción. Entre los ámbitos de competencias complejas que deben desarrollar los universitarios, se encuentran el pensamiento crítico, la capacidad de comprender a iguales y no iguales, la empatía, la inteligencia interpersonal. Saber reconocer los elementos sociales que construyen y favorecen la desigualdad de género esta en la base de esas competencias. Las relaciones de género son el resultado de acciones, transformaciones, rupturas y continuidades acaecidas en los procesos sociales en momentos presentes y pretéritos. Los primeros no pueden explicarse ni entenderse sin los segundos. Por ello, creemos oportuno incorporar en los próximos cursos en la asignatura de sociología de primero de grado la reflexión sobre los conocimientos que reconocen tener sobre los roles de la mujer a lo largo de la historia reciente. Las tareas de los cursos analizados nos aportan datos básicos para fundamentar 
la oportunidad de esa tarea. Una tarea completada con un trabajo reflexivo, guiado didácticamente y bibliográfica, sobre memorias escritas por mujeres reconocidas y también anónimas. Mujeres que no solo escriban sobre sus hazañas durante la guerra civil sino de diferentes momentos históricos. Protagonistas de narrativas que los estudiantes deberán buscar en su proximidad, en los pueblos y ciudades donde viven y puedan dialogar. Tanto su localización como su inexistencia, con la correspondiente reflexión guiada sobre ello, se pretende que sea un ejercicio de gran utilidad y contenido académico y humanístico.

\section{Resultados y conclusiones}

Los datos cuantitativos y de contenido aportados permiten observar interesantes aspectos para la reflexión. El primero es que queda comprobado que, en el espacio geográfico objeto de estudio, el discurso y la mirada que ha construido la memoria de las mujeres ha sido mayoritariamente la masculina. Ello supone sin duda un sesgo de género en la construcción social de los contextos y de las realidades existentes en este periodo. La segunda es que, aunque las muestras de que hemos partido son escasas, queda constatada la gran complejidad de los roles que las mujeres ejercieron durante los años de la guerra civil, complejidad que contrasta con la infravalorización de su posición en el relato de la historia local.

Se evidencia que existe un amplio vacío de información de primera mano sobre las mujeres que vivieron y lucharon en gran parte del territorio. La provincia de Lleida está formada por 229 municipios y 12 comarcas. Tal como se observa en la tabla 1, los espacios desde donde las mujeres han explicado sus hechos se reducen a 5 comarcas y 4 poblaciones. Cierto es que los escritos por ellos recogen un margen territorial más amplio y en ellos, como se ha dicho, las mujeres también aparecen. Con todo, de manera diferente y sin el activismo del relato en primera persona.

La tercera incide en el hecho patente que la ausencia de recuerdo explícito y relatado por las mujeres contribuye de manera significativa a consolidar esa insignificancia histórica con su invisibilización y desconocimiento hecho que se refleja en las tareas académicas. Y contribuye a la vez a que las mujeres no adquieran conciencia de la necesidad social de sus experiencias relatadas. La inexistencia de sus experiencias vividas y explicadas desde sus ópticas específicas significa que una parte cuantitativa y cualitativamente muy importante de nuestra historia reciente queda oculta porque no queda escrita y, por tanto, se olvida.

La cuarta se desprende del análisis de contenido. Se verifica que las memorias escritas por mujeres permiten completar el conocimiento de experiencias, hechos y espacios que tienen matices significativos que solo pueden recuperarse a través del relato de sus propias experiencias.

La última conclusión, derivada de las anteriores, apunta a la necesidad de sensibilizar la población femenina de todas las zonas del territorio que aun puede narrar sus recuerdos del periodo bélico, para recuperarlos. Una necesidad urgente, si cabe, a causa de la edad del colectivo, que sería oportuno enfocar des de la responsabilidad que los científicos sociales tenemos con la recuperación de la memoria histórica y con la correcta (in)formación de las generaciones jóvenes. Es oportuno sin duda incorporar a las generaciones jóvenes de estudiantes universitarios a esa imprescindible empresa social de recuperar la memoria personal y colectiva. Un paso imprescindible relacionado con el aumento de conocimientos y formación para valorizar las aportaciones de las mujeres del territorio. 


\section{Referencias bibliográficas}

\section{De la temática general}

Calero, Ángeles (2020). "Pròleg” a DDAA. Dones de Lleida. De la restauració a la Guerra Civil. Lleida: AlfaZeta.

DDAA. (2010). Dones de Lleida. De la restauració a la Guerra Civil. Lleida: AlfaZeta.

Dekker, Rudolf (2002): “Jacques Presser's Heritage: Egodocuments in the Study of History”. Memoria y civilización, 5, 13-37.

Fernández, Antonia (2001). Las mujeres en la enseñanza de las ciencias sociales. Madrid: Síntesis citado en Sant, Edda; Pagés, Joan. (2011): “¿Por qué las mujeres son invisibles en la enseñanza de la historia?”. Revista Historia y Memoria, 3, 129-146.

Halbwachs, Maurice (2004). Los marcos sociales de la memoria. Barcelona: Anthropos.

Hernández, Francesc J. (2007). En el curs de la vida. Educació, formació, biograficitat i gènere. Xàtiva: Edicions del Centre de Recursos i Educació Contínua.

Hernández, Francesc J. y Villar, Alícia. (eds). (2015). Educación y biografías. Perspecticvas pedagógicas y sociológicas actuales. Barcelona: UOC.

Jané, Oscar; Miralles, Eulalia; Fernández, Ignasi (eds) (2013). Memòria personal. Una altra manera de llegir la bistòria. Barcelona: Universitat Autónoma de Barcelona.

Le Goff, Jacques (1991). Pensar la historia. Barcelona: Paidós.

Prats, Joaquim; Santacana, Joan (2015): "Nous paradigmes en l'ensenyament de la historia". Educació $i$ Història. Revista d'Historia de l'Educació, 26, 19-39.

Sant, Edda; Pagés, Joan. (2011). “¿Por qué las mujeres son invisibles en la enseñanza de la historia?”. Revista Historia y Memoria, 3, 129-146.

Unesco-Catalunya (2015). Repensar l'educació. Vers un bé comú mundial? Barcelona: Centre Unesco de Catalunya.

Verd, Joan Miquel (2006): "La construcción de indicadores biográficos mediante el análisis reticular del discurso. Una aproximación al análisis narrativo - biográfico”. Revista Hispana para el análisis de redes sociales Vol.10, 2-26.

\section{De las narrativas biográficas analizadas}

Brianso, Mercè (1987). Una àvia sentimental: recull de vivències, exemples i opinions. Lleida:Virgili \& Pagès

Farrera, Lola (1998). Posta de sol. Algunes págines de la mena vida. Lleida: Pagès editors

Garrofé, Carme (2010). Protestants sota el franquisme. Repressió religiosa contra la comunitat de Termens. (19391960). Lleida: Pagès editors

Piulats, Isabel (1978). Memorias de doña Isabel Piulats Reñé, viuda de la Guerra Civil Española. Bellpuig: Saladrigues

Sistac, Dolors (2013). Temps de llucar. Lleida: Pagès editors 


\section{Nota biográfica}

Paquita Sanvicén Torné es Profesora Asociada de la Universitat de Lleida. Sus líneas de investigación son: mujeres y migraciones; espacios de socialización y redes de participación de las personas recien llegadas; procesos culturales en Lleida (Guerra Civil, Franquismo y Transición); política lingüística; presencia, roles, papel oficial y real de las mujeres en la transformación social y cultural del territorio de Lleida (s. XX-XXI). 